\title{
Anticorpos Antifosfolípides em Mulheres com Antecedentes de Perdas Gestacionais: Estudo Caso-Controle $e^{(*)}$
}

\section{Antiphospholipid Antibodies in Women with Recurrent Presnancy Loss: a Case-Control Study}

\author{
Olívia Lúcia Nunes Costa ${ }^{(1)}$, Cláudio Brandão(2), Mônica Maria Ribeiro Silva ${ }^{(3)}$, \\ Kleber Santos Pimentel ${ }^{(3)}$, Mittermayer Barreto Santiago ${ }^{(4)}$
}

\section{RESUMO}

Objetivo: determinar a prevalência de anticorpos antifosfolípides em mulheres com antecedentes de perdas gestacionais na população obstétrica em geral e verificar se os anticorpos antifosfolípides representam fator de risco para perdas gestacionais na população estudada. Métodos: foi realizado um estudo caso-controle prospectivo com mulheres grávidas e não grávidas, atendidas numa maternidade pública entre março de 2003 e junho de 2004. As mulheres foram divididas em dois grupos de acordo com o passado obstétrico; 100 mulheres com antecedentes de perdas gestacionais de acordo com a definição estabelecida para o diagnóstico da síndrome antifosfolipídica e que não apresentassem outros fatores relacionados ao insucesso gestacional; 150 mulheres saudáveis com antecedentes de duas ou mais gestações bem sucedidas. A determinação do anticoagulante lúpico (AL) foi feita mediante os testes de TTPA, dRVVT de triagem e dRVVT confirmatório. Para a pesquisa dos anticorpos anticardiolipina (aCL) classes IgG e IgM foi utilizado o teste de ELISA. e os resultados semiquantitativos expressos em unidades GPL e MPL. Resultados: o anticoagulante lúpico estava presente em 5\% das pacientes-caso e $2 \%$ dos controles $(p=0,27)$. Os anticorpos aCL IgG estavam presentes em $18 \%$ das pacientes-caso e $8,7 \%$ das pacientescontrole ( $p=0,028$; OR =2,3; IC 95\%=1-53). Na classe IgM, 5\% de positividade para os casos e $1 \%$ para os controles $(p=0,21)$. Conclusões: os anticorpos antifosfolípides (AL e/ou aCL IgG e/ou IgM) foram mais prevalentes nas mulheres com perdas gestacionais (28\%) que na população obstétrica em geral (17\%). As mulheres com aCL IgG têm duas vezes mais chance de ter perdas gestacionais que a população obstétrica em geral.

Palavras-chave: perdas gestacionais de repetição, anticorpos antifosfolípides, síndrome antifosfolípide.

\begin{abstract}
Objective: To determine the prevalence of antiphospholipid antibodies in women with pregnancy loss and verify if such antibodies represent a risk factor for pregnancy failure. Methods: We performed a case-control study with 250 pregnant and non-pregnant women, seen at a public maternity between March of 2003 and June of 2004. The women were divided in two groups according to their obstetric past: 100 women with previous pregnancy loss, defined as the obstetric criteria of the antiphospholipid syndrome (cases) and 150 healthy women with record of two or more successful pregnancies (controls). Lupus anticoagulant was determined by aTTP and $d R V V T$ tests. $\operatorname{Ig} G$ and $\operatorname{Ig} M$ anticardiolipin antibodies (aCL) were determined by a specific immunoassay (ELISA) and results were expressed as GPL or MPL units. Results: Lupus anticoagulant was positive in $5 \%$ of the cases and $2 \%$ of the controls $(p=0.27)$. The IgG aCL antibodies were present in $18 \%$ of the cases and $8,7 \%$ of the controls $(p=0.028 ; O R=$ 2.3; IC 95\% = 1-53) and IgM aCL in 5\% of the cases and 1\% of the controls $(p=0,21)$. Conclusions: Antiphospholipid antibodies were more prevalent in women with pregnancy loss (28\%) than in general obstetric population (17\%). Women with IgG aCL antibodies have higher chances of pregnancy loss.
\end{abstract}

Keywords: recurrent miscarriage, antiphospholipids antibodies, antiphospholipid syndrome.

\footnotetext{
* Trabalho realizado no Laboratório de Imuno-Obstetrícia da Maternidade Climério de Oliveira, Universidade Federal da Bahia (UFBA), Salvador, BA, Brasil. Este estudo foi parcialmente financiado pelo Conselho Nacional de Pesquisa (CNPq). Recebido em 31/03/2005. Aprovado, após revisão, em 10/05/2005.

1. Departamento de Ginecologia Obstetrícia e Reprodução Humana, UFBA.

2. Hospital Aliança, Salvador, BA, Brasil.

3. Maternidade Climério de Oliveira, UFBA.

4. Núcleo de Reumatologia da Bahia/Escola Bahiana de Medicina e Saúde Pública, Salvador, BA, Brasil.

Endereço para correspondência: Olívia Lúcia Nunes Costa. Rua do Limoeiro, 137, Nazaré, CEP 40.055-150. Salvador, BA, Brasil. Telefax (71) 3237-0118; e-mail: olivialc@ufba.br
} 


\section{INTRODUÇÃO}

Perdas gestacionais de repetição é o termo atualmente empregado em lugar de "mau passado obstétrico", usado freqüentemente na prática clínica para referir-se a mulheres com insucesso reprodutivo ${ }^{(1,2)}$. Tanto uma terminologia quanto outra carecem de uma definição precisa e universalmente aceita, o que dificulta sobremaneira a comparação de resultados.

Duas definições para perdas gestacionais podem ser consideradas: 1) três abortamentos de até 12 semanas ou pelo menos duas gestações interrompidas entre 12 e 24 semanas ou uma perda fetal acima de 24 semanas $^{(3)}$; 2) os critérios de morbidade obstétrica utilizados como parte da definição da síndrome antifosfolipídica (SAF), que consistem em: a) uma ou mais mortes fetais acima de dez semanas, de uma causa desconhecida, estando o feto morfologicamente normal ao exame ultra-sonográfico ou ao exame direto; b) um ou mais partos prematuros, estando o neonato morfologicamente normal, até 34 semanas, motivado por préeclâmpsia, eclâmpsia ou insuficiência placentária; c) três ou mais abortamentos espontâneos e consecutivos de gestações de menos de dez semanas, estando ausentes alterações anatômicas e hormonais maternas e alterações cromossômicas do casal $^{(4)}$.

A auto-imunidade foi inicialmente associada a perdas gestacionais há aproximadamente três décadas ${ }^{(5,6,7)}$ pela descrição da presença de anticorpos antifosfolípides (aPL) em mulheres com insucesso reprodutivo. Destes, destacam-se o anticoagulante lúpico $(\mathrm{AL})$ e os anticorpos anticardiolipinas $(\mathrm{aCL})$, que foram inicialmente descritos e são os mais estudados, conquanto na atualidade a associação com outros auto-anticorpos como antifosfatidilserina ${ }^{(8)}$ e antifosfatidiletanolamina ${ }^{(9)}$ esteja sendo evidenciada.

Os anticorpos antifosfolípides estão presentes em 16\% a $20 \%$ de mulheres com perdas gestacionais ${ }^{(10,11,20)}$, sendo que a prevalência desses anticorpos difere nas populações estudadas em decorrência de uma série de fatores, dentre eles o fator racial ${ }^{(11,12)}$. Este foi também observado em estudo realizado entre portadores de lúpus eritematoso sistêmico (LES) no Estado da Bahia, que revelou maior prevalência de anticorpos antifosfolípides em mulatas que entre brancos e negros ${ }^{(12)}$.

Determinar a freqüência de anticorpos aPL em mulheres com antecedentes de perdas gestacionais, numa maternidade pública do Estado da Bahia, onde é nítida a miscigenação, com predominância de mulatos, por seu histórico de região escravagista, representa uma contribuição para o conhecimento desses anticorpos.
Motivou, também, a realização deste trabalho, a necessidade de conhecer o risco que representa a presença dos anticorpos aPL nessa população, dado que representa um subsídio para o tratamento profilático dessas gestantes, com repercussão favorável sobre o binômio materno-fetal.

\section{MATERIAL E MÉTODOS}

Trata-se de um estudo caso-controle prospectivo com 250 mulheres, grávidas e não grávidas atendidas na Maternidade Climério de Oliveira (MCO), em Salvador, BA, Brasil, entre março de 2003 e junho de 2004.

Mulheres na menacma, com idade variando entre 17 e 40 anos, sendo a maioria mulata, foram convidadas a participar deste estudo, previamente aprovado pelo Comitê de Ética em Pesquisa da MCO. Todas as mulheres incluídas assinaram o Termo de Consentimento Livre e Esclarecido e foram divididas em dois grupos de acordo com o passado obstétrico:

Casos: 100 mulheres com antecedentes de perdas gestacionais, de acordo com a definição estabelecida para morbidade obstétrica da $\mathrm{SAF}^{(4)}$, estando ausentes outros fatores relacionados ao insucesso gestacional. Foram excluídas as pacientes com diagnóstico de LES ou qualquer outra doença difusa do tecido conjuntivo.

Controles: 150 mulheres saudáveis com antecedentes de duas ou mais gestações bem sucedidas.

\section{TESTES LABORATORIAIS}

A pesquisa do AL foi realizada utilizando-se os testes de tempo de tromboplastina parcial ativada (TTPA) e o diluted Russell's venon time (dRVVT), (triagem e confirmatório). A coleta de sangue foi realizada estando as pacientes em jejum e o plasma obtido após duas centrifugações de 15 minutos cada. A leitura do tempo de coagulação foi realizada utilizando-se o coagulômetro digital de dois canais da Tecnika. Todos os passos da reação ocorreram à temperatura ambiente, na seqüência: 1) TTPA e dRVVT de triagem do plasma em estudo; 2) quando o tempo de coagulação do TTPA era prolongado, misturava-se o plasma testado com o plasma normal na proporção de $1: 1 ; 3$ ) quando o dRVVT e o TTPA com mistura eram prolongados, utilizava-se o dRVVT confirmatório. Neste exame, a positividade era representada pela diminuição ou a normalização do tempo de coagulação. O tempo de coagulação foi expresso como resultado da relação: tempo de coagulação da amostra/tempo de coagulação do controle (pool de 
pacientes normais), considerando-se normais os valores entre 0,5 e 1,2 .

A pesquisa dos aCL das classes $\operatorname{IgG}$ e IgM foi realizada como descrito previamente ${ }^{(13)}$, com algumas modificações: Método de ELISA: utilizou-se placa de poliestireno, a qual foi sensibilizada com $50 \mu \mathrm{l} /$ orifício de uma solução de cardiolipina (Sigma) dissolvida em etanol numa concentração de $50 \mu \mathrm{g} / \mathrm{ml}$. O solvente foi evaporado e a placa foi incubada por uma hora com $100 \mu \mathrm{l}$ /orifício de soro fetal bovino a 10\% em PBS (FCS a 10\%) para bloquear sítios antigênicos inespecíficos na placa. Cada soro a ser testado (diluído a 1/ 50 em FCS a 10\%) foi incubado por três horas. Como segundo anticorpo foi utilizado um conjugado de peroxidase com anti-IgG humano diluído a 1/10.000 em FCS a 10\%. Após incubação de uma hora, foram adicionados $50 \mu \mathrm{l} /$ orifício do substrato (TBM). Essa reação enzimática foi posteriormente interrompida com $50 \mu \mathrm{l}$ /orifício de $\mathrm{H}_{2} \mathrm{SO}_{4}$ (ácido sulfúrico) e a leitura da placa foi realizada usando-se fotômetro automático. Após cada período de incubação da reação, a placa foi lavada três vezes com PBS. Todos os passos da reação ocorreram à temperatura ambiente. Foram usados calibradores internacionais (Lousville APL Diagnostics) e os resultados foram expressos em unidades IgG (GPL) ou IgM (MPL), de acordo com os graus de positividade: positivo alto $>80$ unidades; positivo moderado $\geq 20$-80 unidades; positivo fraco $\geq 10<20$ unidades.

Para a análise estatística foi utilizado o programa SPSS versão 9.0. A presença de associação entre os grupos caso e controle e os parâmetros qualitativos foram verificados pelo teste do qui-quadrado ou teste exato de Fischer. Foi considerado um resultado com significância estatística quando a probabilidade (p) do erro $\alpha$ foi igual ou inferior a $5 \%$ ( $p \leq 0,05)$. Utilizou-se como teste de concordância entre as variáveis o índice de Kappa ${ }^{(14)}$, cujo resultado varia entre 0 e 1 com a seguinte distribuição da concordância: $<0,20$ ruim; 0,20 a 0,40 razoável; 0,40 a 0,60 moderada; 0,60 a 0,80 boa e 0,80 a 1,0 muito boa.

\section{RESULTADOS}

A idade das 100 mulheres com antecedentes de perdas gestacionais variou entre 17 e 37 anos (média=28,7 e $\mathrm{DP}=6,1)$. Nas 150 pacientes-controle a idade variou entre 17 e 40 anos (média=27,6 e $\mathrm{DP}=6,1$ ). As pacientes não foram estratificadas de acordo com o tipo racial, contudo predominaram aquelas de cor mulata.

O AL estava presente em 5\% das pacientes-caso e em três $(2 \%)$ das 150 pacientes-controle $(\mathrm{p}=0,27)$.
Os anticorpos aCL da classe IgG estavam presentes em $18 / 100(18 \%)$ das pacientes com antecedentes de perdas gestacionais e em 13/150 (8,7\%) daquelas com gestações bem sucedidas $(\mathrm{p}=0,028$; OR $=2,3$; IC 95\% $=1-5,3)$. Das pacientes-caso, os 18 soros positivos para aCL estavam assim distribuídos: cinco + fraco; oito + moderado e cinco + forte. Nos controles, dos 13 soros positivos, quatro foram + fraco, oito + moderado e um + forte.

Os anticorpos aCL IgM estavam presentes em 5/96 (5,2\%) das pacientes com perdas gestacionais e em 1/92 (1\%) daquelas com gestações bem sucedidas $(\mathrm{p}=0,21)$.

No total, os aPL (AL e/ou aCL IgG e/ou IgM) estavam presentes em $28 \%$ das mulheres com antecedentes de perdas gestacionais e em 17\% na população obstétrica em geral.

Entre as 100 pacientes com perdas gestacionais, cinco apresentaram história de fenômenos tromboembólicos que não foram referidos pelas 150 mulheres com gestações bem sucedidas. Dessas, duas referiram história pregressa de trombose venosa profunda; porém, curiosamente, a pesquisa dos anticorpos aFL mostrou-se negativa. Duas apresentaram tromboflebite e em ambas apenas os aCL IgG estavam presentes com títulos moderado e alto. Uma paciente apresentou acidente vascular cerebral e nela estavam presentes o AL e os anticorpos aCL IgG e IgM.

$\mathrm{O}$ índice Kappa nas pacientes-caso para as variáveis anticoagulante lúpico x aCL IgG; AL x aCL IgM e AL x aCL IgG e/ou IgM foi de 0,10; 0,15 e 0,11, respectivamente. $\mathrm{O}$ mesmo índice para as pacientes com gestações bem sucedidas para as variáveis AL x aCL IgG; AL x aCL IgM e AL $x$ aCL $\operatorname{IgG}$ e/ou IgM os resultados foram 0,096; 0 e 0,083 , respectivamente.

\section{DISCUSSÃO}

A freqüência dos aPL (AL e/ou aCL IgG e/ou IgM) observada no presente estudo foi de $17 \%$ em mulheres com gestações bem sucedidas e de $28 \%$ naquelas com antecedentes de perdas gestacionais, enquanto na literatura esses números variam de $2 \%$ a $14 \%$ na população obstétrica em geral ${ }^{(10,15)}$, e de $20 \%$ a $40 \%$, nas mulheres com insucesso reprodutivo ${ }^{(10,16)}$. Essa variação na freqüência desses anticorpos pode se dever, dentre outras razões, ao fator racial. Em um trabalho realizado nessa mesma região entre pacientes lúpicos, foi verificada maior freqüência dos anticorpos aFL em pacientes mulatos que entre os negros e brancos ${ }^{(12)}$.

Adicionalmente, outros pontos devem ser considerados no que se refere à ampla faixa de freqüência descrita para os anticorpos aPL em gestantes: 1) seleção dos casos, parti- 
cularmente entre as mulheres com perdas gestacionais, mas cuja definição não é uniforme nos diversos estudos; 2) determinação apenas dos aCL, ou de ambos (aCL + AL) como ocorreu neste trabalho; 3) variação na metodologia laboratorial empregada, a despeito da busca de padronização universal para a determinação dos anticorpos aPL.

Quando analisado separadamente, o AL foi encontrado em 5\% das mulheres com perdas gestacionais e $2 \%$ naquelas com gestações bem sucedidas, dados que coincidem com registros prévios da literatura ${ }^{(17,18)}$.

Os anticorpos aCL, da classe IgG, foram identificados em $8,7 \%$ das mulheres com gestações bem sucedidas e em 18\% daquelas com antecedentes de perdas gestacionais, sendo observada uma diferença estatisticamente significativa entre os dois grupos. Avaliação de risco evidenciou que as portadoras de anticorpos aPL têm duas vezes mais chance de apresentarem insucesso reprodutivo que a população obstétrica em geral. Inúmeros autores ${ }^{(19-22)}$ destacam a importância dos anticorpos aCL IgG, particularmente com títulos médios e elevados, em pacientes com SAF primária ou secundária, relacionando-os com complicações clínicas. Do ponto de vista obstétrico, esse resultado reveste-se da maior importância porque traduz a necessidade de incorporar a pesquisa dos aPL na propedêutica das pacientes com perdas gestacionais.

Neste material os anticorpos aCL IgM estavam presentes em $5 \%$ dos casos e em 1\% dos controles. Como a presença desses anticorpos com títulos baixos e transitórios pode ser

\section{REFERÊNCIAS}

1. Li TC, Makris M, Tomsu M, Tuckerman E, Laird S: Recurrent miscarriage: aetiology, management and prognosis. Hum Reprod Update. 8: 463-81, 2002.

2. Gadelha A, Manad Filho F, Ferreira AC: Síndrome Antifosfolípide Importante causa de perda fetal recorrente. GO Atual 5: 8-10, 2003.

3. Brenner B, Sarig G, Weiner Z, Younis J, Blumenfeld Z, Lanir N: Thrombophilic polymorphisms are common in women with fetal loss without apparent cause. Thromb Haemost 82: 6-9, 1999.

4. Wilson WA, Gharavi AE, Koike T, et al: International consensus statement on preliminary classification criteria for definite antiphospholipid syndrome: report of an international workshop. Arthr Rheum 42: 1309-11, 1999.

5. Nilsson IM, Astedt B, Hedner U, Berezin D: Intrauterine death and circulating anticoagulant ("antithromboplastin"). Acta Med Scand 197: 153-9, 1975.

6. Branch DW, Andres R, Digre KB, Rote NS, Scott JR: The association of antiphospholipid antibodies with severe preeclampsia. Obstet Gynecol 73: 541-5, 1989.

7. Pattison NS, Chamley LW, McKay EJ, Liggins GC, Butler WS: Antiphospholipid antibodies in pregnancy: prevalence and clinical associations. Br J Obstet Gynaecol 100: 909-13, 1983. secundária à exposição a drogas e infecção, a baixa freqüência encontrada neste trabalho pode ser atribuída à rigorosa seleção dos casos.

A pouca concordância, evidenciada pelo índice Kappa, no achado simultâneo dos anticorpos (aCL e AL), tanto nos casos como nos controles, torna imprescindível a pesquisa de ambos na investigação das causas de perdas gestacionais, conforme preconizado para o diagnóstico da SAF.

O achado de 5\% de fenômenos tromboembólicos em mulheres com perdas gestacionais sugere que a presença dos aPL (em três delas) possa ter favorecido tais ocorrências.

No presente estudo, apesar de algumas mulheres com anticorpos aPL apresentarem perdas gestacionais e fenômenos trombóticos sugerindo a presença da SAF, tomouse o cuidado de não classificá-las como portadoras dessa síndrome, uma vez que os testes laboratoriais não foram repetidos e confirmados com intervalo superior a seis semanas - como preconizado pelos critérios diagnósticos ${ }^{(4)}$.

Em conclusão, os resultados deste trabalho mostram claramente que os anticorpos aPL, mais particularmente aCL classe IgG, detectados em 18\% das mulheres com antecedentes de perdas gestacionais sem causa aparente, representam um fator de risco para tal condição. Adicionalmente, a identificação das portadoras da SAF entre as mulheres com perdas gestacionais é de grande importância clínica, uma vez que dá subsídios para o tratamento profilático com repercussão favorável para o binômio materno-fetal.

8. McCowan LM, Chamley LW: Antiphosphatidyl serine antibodies are more common in normotensive women with small for gestational age pregnancies. Aust N Z J Obstet Gynaecol 44: 14-88, 2004.

9. Sugi $\mathrm{T}$, Matsubayashi $\mathrm{H}$, Inomo A, Dan L, Makino $\mathrm{T}$ : Antiphosphatidylethanolamine antibodies in recurrent early pregnancy loss and mid-to-late pregnancy loss. J Obstet Gynaecol Res 30: 326-32, 2004.

10. Pereira MD, Menegoci JC: Mecanismos imunológicos relacionados ao aborto recorrente. Femina 30: 175-80, 2002.

11. Gharavi AE, Santiago MB: Antiphospholipid Antibodies: Characteristics and origin. JIRA 7: 125-31, 1999.

12. Travassos AC, Rocha MC, Souza S, Brandão C, Silva JF, Santiago M: Freqüência dos anticorpos antifosfolípides (aFL) em portadores de lúpus eritematoso sistêmico (LES) no Estado da Bahia. Rev Bras Reumatol 40: 183-8, 2000.

13. Gharavi AE, Harris EN, Asherson RA, Hughes GRV: Antiphospholipid antibodies: isotype distribution and phospholipid specificity. Ann Rheum Dis 46: 1-6, 1987.

14. Glantz SA: Primer of Bioestatistics. 5th Mc grow-Hill, 2002.

15. Chandramouli NB, Rodgers GM. Management of thrombosis in women with antiphospholipid syndrome. Clin Obstet Gynecol 44: 36-47, 2001. 
16. Schved JF, Dupuy-Fons C, Biron C, Quere I, Janbon C: A prospective epidemiological study on the occurrence of antiphospholipid antibody: the Montpellier Antiphospholipid (MAP) Study Haemostasis 24: 175-82, 1994.

17. Costa ALFF: Autoimunidade e Perda Conceptual. Tese de Doutoramento apresentada à Faculdade de Medicina de Ribeirão Preto, USP, 1994.

18. Ferriani RA, Moura MD, Costa ALFF, Barbosa JE, Sá MFS, Sala MM: Auto-imunidade e perda conceptual. Femina 20: 27-30, 1992.
19. Concepción LAD: El Síndrome Antifosfolípidio. Rev Cubana Hematol Immunol Hemot 14: 67-79, 1998.

20. Daboubi MK: Anticardiolipin antibodies in women with recurrent abortion. East Mediterr Health J 7: 95-9, 2001.

21. Geis W, Branch W: Obstetric Implications of Antiphospholipid antibodies: Pregnancy Loss and Other Complications. Clin Obstet Gynecol 44: 2-10, 2001.

22. Shehata HA, Nelson-Piercy C, Khamashta MA: Management of pregnancy in antiphospholipid syndrome. Rheum Dis Clin North Am 27: 643-59, 2001. 